\title{
Aplikasi Penyaluran Bibit Perkebunan Berbasis Web Pada Dinas Perkebunan Kabupaten Pasaman Barat
}

\author{
Nelfira $^{1}$, Suardinata ${ }^{2}$, Nunuk Parwati ${ }^{3}$ \\ 1,2,3 STMIK Indonesia Padang \\ e-mail: ${ }^{1}$ nelfira@stmikindonesia.ac.id, ${ }^{2}$ suardinata@stmikindonesia.ac.id, \\ 3nunukparwati36@gmail.com
}

\begin{abstract}
Abstrak
Dinas Perkebunan kabupaten Pasaman Barat mempunyai program kegiatan penyaluran bibit perkebunan kepada kelompok tani. Petani mendapatkan informasi penyaluran bibit dari sosialisasi yang dilakukan oleh Dinas Perkebunan tersebut. Sistem yang berjalan saat ini menyulitkan petani mengetahui keberadaan bibit karena kurangnya informasi tentang penyaluran bibit, proses pengolahan data penyaluran bibit di Dinas Perkebunan Kabupaten Pasaman Barat sering mengalami kesalahan dan hasil laporan penyaluran bibit mengalami keterlambatan karena proses pencarian data yang lama. Untuk itu perlu dirancang aplikasi penyaluran bibit perkebunan berbasis web dengan menggunakan bahasa pemograman PHP dan MySQL sebagai basis data. Perancangan aplikasi menggunakan metode SDLC model waterfall dengan alat bantu perancangan UML. Hasil akhir dari penelitian ini adalah terciptanya Aplikasi Penyaluran Bibit Perkebunan Berbasis Web pada Dinas Perkebunan Kabupaten Pasaman Barat. Dengan aplikasi ini petani bisa mengetahui informasi keberadaan bibit dan proses pengolahan data penyaluran bibit perkebunan menjadi lebih cepat, tepat, akurat, dan relevan.
\end{abstract}

Kata kunci: Aplikasi, Penyaluran Bibit, Web, PHP, MySQL

\section{Abstract}

Dinas Perkebunan Kabupaten Pasaman Barat has a program to distribute plantation seeds to farmer groups. Farmers get information on seedling distribution from the socialization carried out by the Dinas Perkebunan. The current system makes it difficult for farmers to know the whereabouts of seedlings due to lack of information about seedling distribution, the data processing process of seedling distribution at the Dinas Perkebunan Kabupaten Pasaman Barat often experiences errors and the results of seedling distribution reports experience delays due to the old data search process. Web-based plantation seedling distribution application was developed using PHP and MySQL programming languages as a database. Application design uses SDLC method waterfall model with UML design tools. The final result of this study is the creation of a Web-Based Plantation Seed Distribution Application at the Dinas Perkebunan Kabupaten Pasaman Barat. With this application, farmers can find out information about the existence of seeds and the data processing process of distributing plantation seeds to be faster, precise, accurate, and relevant.

Keywords : Application, Distribution of Seeds, Web, PHP, MySQL

\section{Pendahuluan}

Perkembangan Teknologi (Budiman, 2017) pada dunia global tidak dapat dipisahkan dalam kehidupan sehari-hari, hampir setiap kantor (Sidik, Dan, Pi, Julianto, \& Tedyyana, 2019), industri (Erna Kumalasari Nurnawati, 2018), akademik (Atmojo \& Sistem, 2019), pemerintahan bahkan masyarakat memakai perangkat komputer untuk berbagai keperluan.
Kemajuan teknologi (Alexander Setiawan, 2010)yang semakin pesat tidak lepas dari campur tangan manusia dalam melakukan hal yang baru. Salah satu penggunaan teknologi komputer yaitu penggunaan sistem informasi yang terkomputerisasi dan terintegrasi (Arman, Wahyudi, 2019), sehingga seluruh aktifitas dapat dilakukan dengan optimal dan efisien. Penggunaan teknologi komputer dan teknologi 
komunikasi menghasilkan sebuah penggabungan sistem informasi yang saat ini mudah untuk diakses tanpa adanya batasan waktu (Arman, Elizamiharti, \& Muhammad Saf'an, 2019).

Dinas Perkebunan Kabupaten Pasaman Barat mempunyai program kegiatan penyaluran bibit perkebunan kepada kelompok tani (SAPUTRA, ANGGRENI, \& DHARMA, 2017). Bibit ini akan membantu petani dalam meningkatkan perekonomian petani. Dalam proses penyaluran bibit perkebunan, petani mendapatkan informasi dari sosialisasi yang dilakukan oleh Dinas Perkebunan Kabupaten Pasaman Barat (Oksatriandhi \& Santoso, 2014), dengan syarat kelompok tani tersebut mengajukan proposal dan memiliki lahan pertanian. Dinas Perkebunan Kabupaten Pasaman Barat memasok bibit perkebunan dari waralaba, bibit yang disalurkan oleh Dinas Perkebunan Kabupaten Pasaman Barat kepada kelompok tani yaitu kelapa sawit, kakao, nilam, kopi, dan kelapa.

Adapun pengolahan, penyaluran, penyimpanan, dan pembuatan laporan bibit pada Dinas Perkebunan Kabupaten Pasaman Barat masih menggunakan semi komputer dalam pengolahan data, serta proses penyimpanan data serta pembuatan laporan saat ini diarsipkan dalam bentuk file (Wardiana, 2002), sehingga mengakibatkan kesulitan dalam pencarian informasi penyaluran bibit kepada petani dan juga memungkinkan terjadinya kesalahan dalam pemrosesan data. Hal ini kurang efektif, karena dapat terjadi kesalahan dalam pencatatan dan penerimaan penyaluran bibit yang dilakukan (Loveri, 2007).

Pentingnya sebuah informasi mengharuskan kita untuk dapat menyampaikan informasi dengan jelas dan menarik kepada semua orang (Yendra Aprilla, 2018). Di Dinas Perkebunan Kabupaten Pasaman Barat informasi sangat dibutuhkan untuk membantu pegawai maupun kepala dinas dalam mengambil sebuah kebijakan, maka dari itu dengan adanya aplikasi yang akan dirancang nantinya sebagai pengolah data penyaluran bibit akan membantu pegawai dalam melaksanakan tugasnya dengan maksimal.

Aplikasi didefinisikan sebagai program siap pakai yang dapat digunakan untuk menjalankan perintah-perintah dari pengguna aplikasi tersebut dengan tujuan mendapatkan hasil yang lebih akurat sesuai dengan tujuan pembuatan aplikasi tersebut. aplikasi adalah program siap digunakan dan dapat untuk menjalankan semua perintah dari penggunka aplikasi tersebut dengan harapan dapat menghasilkan informasi yang lebih akuran, terpecaya sesuai dengan tujuan perancangan aplikasi yang sudah ditentikan terlebih dahulu (Abdurahman \& Riswaya, 2014).

Pengertian penyaluran dimaksudkan sebagai distribusi (pembagian, pengiriman) kepada beberapa orang atau beberapa tempat. Sedangkan menurut Distribusi dapat dimengerti sebagai proses penyaluran barang atau jasa kepada pihak lain (Click et al., n.d.). Bibit adalah tumbuhan muda calon pohon yang dihasilkan dari benih.

\section{Metode Penelitian}

Metode penelitian yang digunakan pada penelitian ini adalah (Yasdomi, 2015):

\subsection{Penelitian lapangan}

Pengumpulan data dilakukan pada objek penelitian dengan cara sebagai berikut:

a. Wawancara (Interview)

Mewawancarai secara langsung setiap personil yang terlibat pada Dinas Perkebunan kabupaten Pasaman Barat.

b. Observasi

Melakukan pengamatan langsung terhadap sistem yang sedang berjalan saat ini, dan melihat bibit yang akan disalurkan kepada kelompok tani serta dokumen laporan data penyaluran bibit.

\subsection{Penelitian Kepustakaan}

Metode pengumpulan data dengan mempelajari referensi-referensi yang berhubungan dengan aplikasi penyaluran bibit berbasis web sebagai landasan teori yang dapat memperkuat penelitian ini.

\subsection{Penelitian Laboratorium (laboratorium research) \\ Data yang telah dikumpulkan kemudian} diolah dengan menggunakan hardware dan software, yang terpasang pada sebuah Personal Computer (PC)

2.4. Model Pengembangan Perangkat lunak Model pengembangan perangkat lunak yang digunakan pada penelitian ini adalah model SDLC air terjun (Dian \& Pratiwi, 2017) 
(waterfall) atau sering juga disebut model sekuensial linier (sequential liniear). Model air terjun menyediakan pendekatan alur hidup perangkat lunak secara sekuensial atau terurut dimulai dari analisis, desain, pengodean, pengujian, dan tahap pendukung. Untuk lebih jelas dapat dilihat pada Gambar 1.

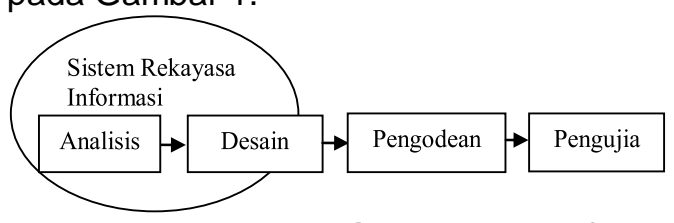

Gambar 1 llustrasi Model Waterfall

a. Analisis kebutuhan perangkat lunak Proses pengumpulan kebutuhan dilakukan secara intensif untuk menspesifikasikan kebutuhan perangkat lunak agar dapat dipahami perangkat lunak seperti apa yang dibutuhkan oleh user.

b. Desain

Desain perangkat lunak adalah proses multi langkah yang fokus pada desain pembuatan program perangkat lunak termasuk struktur data, arsitektur perangkat lunak, representasi antar muka, dan prosedur pengodean. Tahap ini mentranslasi kebutuhan perangkat lunak dari tahap analisis kebutuhan ke representasi desain agar dapat di implementasikan menjadi program pada tahap selanjutnya.

c. Pembuatan kode program

Desain harus ditranslasikan ke dalam program perangkat lunak. Hasil dari tahap ini adalah program komputer sesuai dengan desain yang telah dibuat pada tahap desain.

d. Pengujian

Pengujian fokus pada perangkat lunak dari segi logik dan fungsional dan memastikan bahwa semua bagian sudah diuji. Hal ini dilakukan untuk meminimalisir kesalahan (error) dan memastikan keluaran yang dihasilkan sesuai dengan yang diinginkan.

\section{Hasil dan Pembahasan}

Analisis sistem saat ini dalam proses penyaluran bibit perkebunan adalah petani mendapatkan informasi dari sosialisasi yang dilakukan oleh Dinas Perkebunan Kabupaten Pasaman Barat. Dengan syarat kelompok tani tersebut mengajukan proposal dan memiliki lahan pertanian. Dinas Perkebunan Kabupaten Pasaman
Barat memasok bibit perkebunan dari waralaba, jumlah bibit yang disalurkan kepada kelompok tani tergantung volume kegiatan dan komoditi. Bibit yang disalurkan datangnya tidak selalu tepat waktu, sehingga tidak ada kepastian datangnya bibit dari waralaba kepada Dinas Perkebunan Kabupaten Pasaman Barat yang mengakibatkan kelompok tani tidak mengetahui informasi keberadaan bibit. Untuk itu dibutuhkan sebuah aplikasi penyaluran bibit perkebunan berbasis web. Hal ini sangat penting karena keberadaan aplikasi penyaluran bibit perkebunan dapat membantu anggota Dinas perkebunan menjadi lebih mudah menginput data ke komputer, dan mempermudah kelompok tani mendapatkan informasi tentang penyaluran bibit dari Dinas Perkebunan Kabupaten Pasaman Barat. Laporan penyaluran bibit akan didapat secara otomatis yang dapat diakses kapanpun dan dimanapun, sehingga memudahkan pihak dinas dalam mengelola pemasukan dan pengeluaran bibit perkebunan.

Analisis sistem yang diusulkan berupa rancangan sebuah aplikasi penyaluran bibit perkebunan yang dapat diakses oleh kelompok tani melalui jaringan internet. Aplikasi ini akan membantu kelompok tani dalam penyebaran informasi penyaluran bibit perkebunan setiap saat dimanapun berada. Analisis sistem yang diusulkan digambarkan dengan use case diagram. Use case diagram menyajikan interaksi antara use case diagram dan aktor. Dimana aktor dapat berupa orang, peralatan, atau sistem lain yang berinteraksi dengan sistem yang sedang dibangun. Use Case menggambarkan fungsionalitas sistem atau persyaratan-persyaratan yang harus dipenuhi sistem dari pandangan pemakai. Use case diagram dapat dilihat pada Gambar 2. 


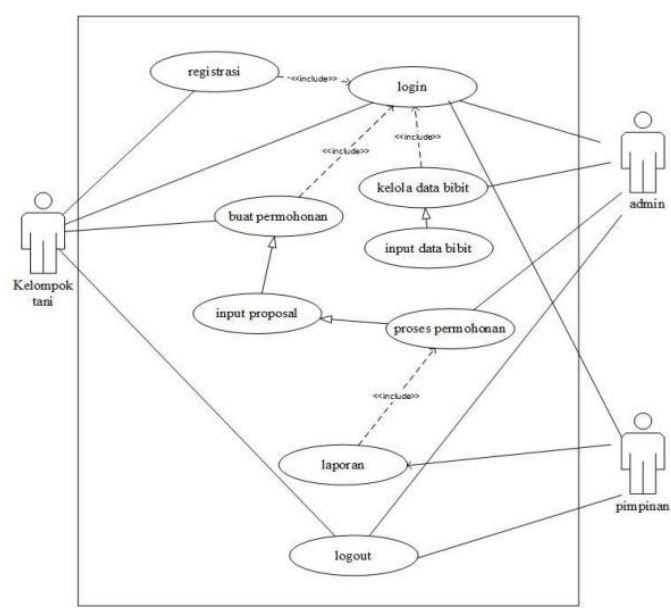

Gambar 2 Use Case Diagram

Dari gambar diagram Use Case diagram di atas dapat dijelaskan sebagai berikut:

1. Definisi aktor

Deskripsi pendefinisian aktor pada aplikasi penyaluran bibit perkebunan dapat dilihat pada Tabel 1.

Tabel 1 Definisi Aktor

\begin{tabular}{|c|c|l|}
\hline & \multicolumn{1}{|c|}{ Aktor } & \multicolumn{1}{|c|}{ Deskripsi } \\
\hline 1. & Kelompok tani & $\begin{array}{l}\text { Orang yang } \\
\text { mengajukan dan } \\
\text { permohonan dan } \\
\text { berhak melakukan } \\
\text { hak akses untuk } \\
\text { mendapatkan bibit } \\
\text { bantuan } \\
\text { perkebunan. }\end{array}$ \\
\hline 2. & Admin & $\begin{array}{l}\text { Orang yang } \\
\text { bertugas dan } \\
\text { memiliki hak akses } \\
\text { untuk melakukan } \\
\text { operasi } \\
\text { penyaluran bibit } \\
\text { perkebunan. }\end{array}$ \\
\hline 3. & Pimpinan & $\begin{array}{l}\text { Orang yang } \\
\text { mempunyai } \\
\text { wewenang broses } \\
\text { terhadap prab biban } \\
\text { penyaluran bit } \\
\text { perkebunan. }\end{array}$ \\
\hline
\end{tabular}

\section{Definisi Use Case}

Deskripsi pendefinisian prilaku aktor pada aplikasi penyaluran bibit perkebunan dapat dilihat pada Tabel 2.
Tabel 2 Definisi Use Case

\begin{tabular}{|c|c|c|}
\hline No. & Use Case & Desk \\
\hline 1. & Registrasi & $\begin{array}{l}\text { Merupakan proses } \\
\text { pendaftaran } \\
\text { kelompok tani } \\
\text { untuk } \\
\text { mendapatkan hak } \\
\text { akses dalam } \\
\text { melakukan proses } \\
\text { penyaluran bibit } \\
\text { perkebunan. }\end{array}$ \\
\hline 2. & Login & $\begin{array}{l}\text { Merupakan proses } \\
\text { untuk melakukan } \\
\text { login ke aplikasi } \\
\text { oleh admin, } \\
\text { pimpinan dan } \\
\text { kelompok tani. }\end{array}$ \\
\hline 3. & $\begin{array}{c}\text { Kelola data } \\
\text { bibit }\end{array}$ & $\begin{array}{l}\text { Merupakan proses } \\
\text { pengelolaan data } \\
\text { bibit oleh admin. }\end{array}$ \\
\hline 4. & $\begin{array}{l}\text { Input data } \\
\text { bibit }\end{array}$ & $\begin{array}{l}\text { Merupakan proses } \\
\text { untuk melakukan } \\
\text { pengentrian data } \\
\text { bibit oleh admin. }\end{array}$ \\
\hline 5. & $\begin{array}{c}\text { Buat } \\
\text { permohonan }\end{array}$ & $\begin{array}{l}\text { Merupakan proses } \\
\text { permohonan yang } \\
\text { akan dibuat oleh } \\
\text { kelompok tani. }\end{array}$ \\
\hline 6. & $\begin{array}{c}\text { Input } \\
\text { proposal }\end{array}$ & $\begin{array}{l}\text { Merupakan proses } \\
\text { penginputan } \\
\text { proposal yang } \\
\text { akan dilakukan } \\
\text { oleh kelompok } \\
\text { tani. }\end{array}$ \\
\hline 7. & $\begin{array}{c}\text { Proses } \\
\text { permohonan }\end{array}$ & $\begin{array}{l}\text { Merupakan proses } \\
\text { permohonan yang } \\
\text { dilakukan oleh } \\
\text { kelompok tani. }\end{array}$ \\
\hline 8. & Laporan & $\begin{array}{l}\text { Merupakan proses } \\
\text { pembuatan } \\
\text { laporan oleh admin } \\
\text { yang akan dilihat } \\
\text { oleh pimpinan. }\end{array}$ \\
\hline 9. & Log out & $\begin{array}{l}\text { Merupakan proses } \\
\text { untuk melakukan } \\
\text { log out dari aplikasi } \\
\text { oleh admin, } \\
\text { pimpinan dan } \\
\text { kelompok tani. }\end{array}$ \\
\hline
\end{tabular}

perkebunan berbasis web
diimplementasikan pada dinas perkebunan Kabupaten Pasaman Barat. Implementasi antar muka menggambarkan tampilan dari sistem yang dibangun. Berikut ini adalah 
implementasi antar muka dari sistem yang dibangun:

1. Menu Utama

Menu utama merupakan halaman utama yang akan keluar pertama kali ketika mengakses sistem. Menu utama ini terdiri dari home, bibit, kontak, serta daftar dan login untuk kelompok tani. Menu utama sistem dapat dilihat pada Gambar 3.

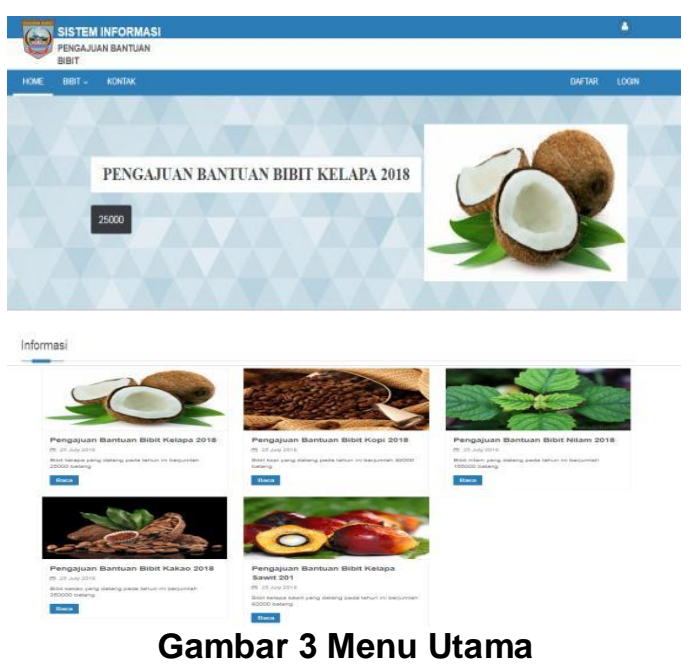

\section{Menu Utama Admin}

Menu utama merupakan halaman yang akan keluar pertama kali ketika admin telah melakukan login pada sistem. Menu utama admin ini terdiri dari home, permohonan, bibit, kategori bibit, informasi, kecamatan, nagari, kelompok tani dan pimpinan. Menu utama admin dapat dilihat pada Gambar 4.

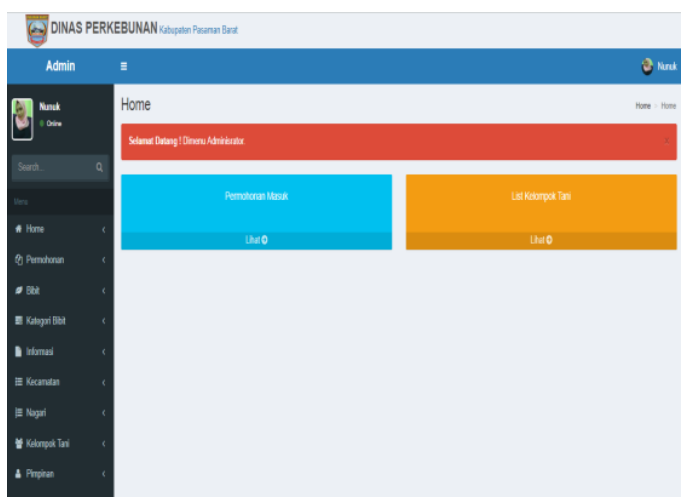

Gambar 4 Menu Utama Admin

\section{Input Pendaftaran Kelompok Tani}

Halaman pendaftaran kelompok tani berfungsi untuk kelompok tani mendaftar sebagai anggota agar dapat melakukan login ke sistem dan melakukan pendaftaran secara online. Tampilan form registrasi kelompok tani dapat dilihat pada Gambar 5.

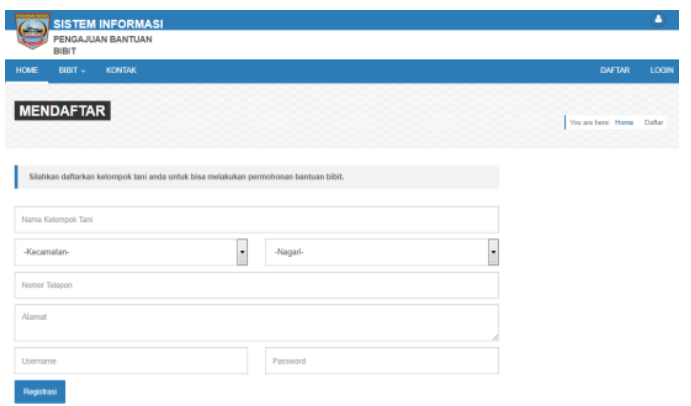

Gambar 5. Form Pendaftaran

Kelompok Tani

\section{Form Login Kelompok Tani}

Halaman login kelompok tani bertujuan untuk membatasi hak akses pengguna dalam menggunakan sistem yang ada. Dengan kata lain sistem ini hanya dapat digunakan oleh kelompok tani yang telah mendaftar. Tampilan halaman login kelompok tani dapat dilihat pada Gambar 6 .

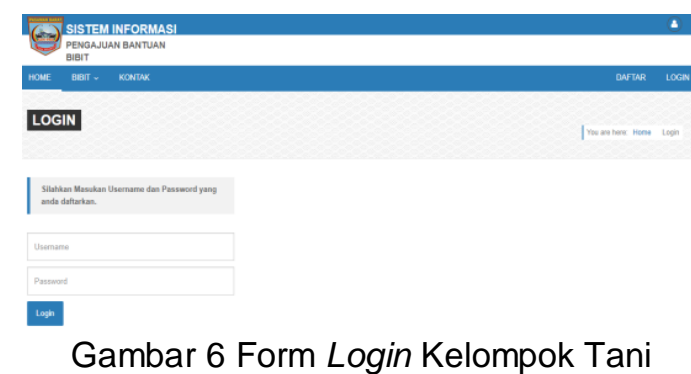

5. Input Permohonan

Form permohonan untuk mengentrkan data permohonan. Form permohonan dapat dilihat pada Gambar 7.

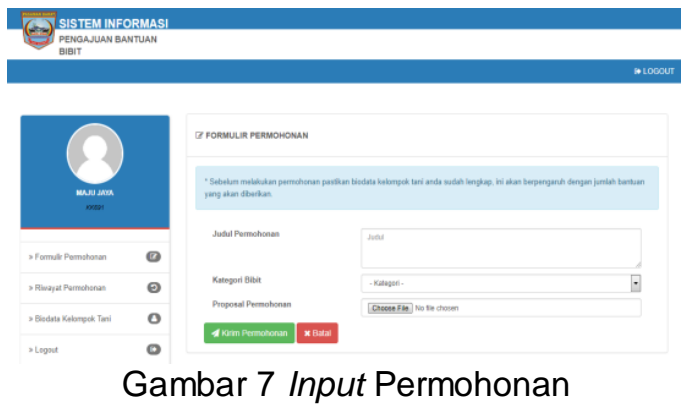

\section{6.. Form Login Admin}

Halaman login admin bertujuan untuk membatasi hak akses pengguna dalam menggunakan sistem yang ada. Dengan kata lain sistem ini hanya dapat digunakan oleh admin saja. Tampilan 
halaman login admin dapat dilihat pada Gambar 8.

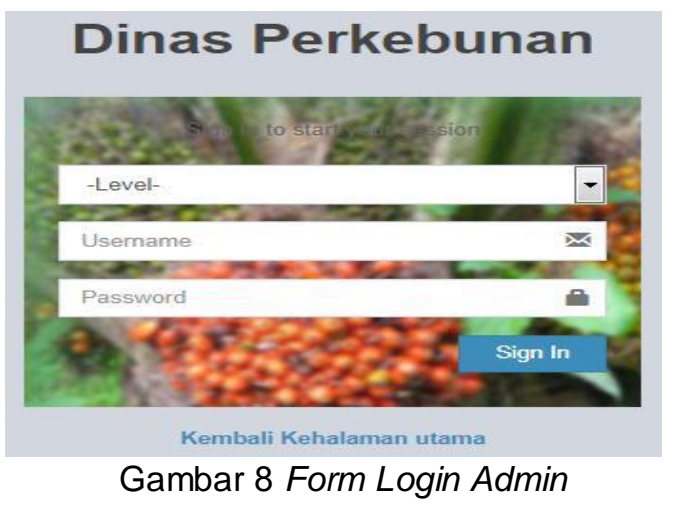

7. Laporan Penerima Penyaluran Bibit Laporan penerima penyaluran bibit berisi data-data penerima bibit. Laporan penerimaan bibit dapat dilihat pada Gambar 9.

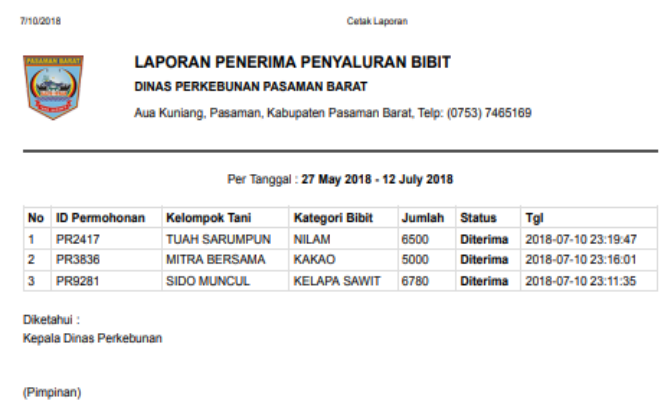

Gambar 9 Laporan Penerima Penyaluran Bibit

\section{Laporan Anggaran Bibit}

Laporan anggaran bibit berisi detail laporan data-data bibit. Laporan anggaran bibit dapat dilihat pada Gambar 10.

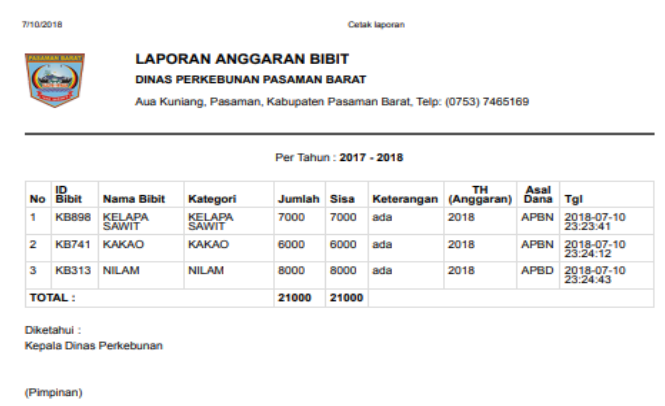

Gambar 10 Laporan Anggaran Bibit

\section{Laporan Data Kelompok Tani}

Laporan data kelompok tani berisi data kelompok tani. Laporan data kelompok tani dapat dilihat pada Gambar 11.

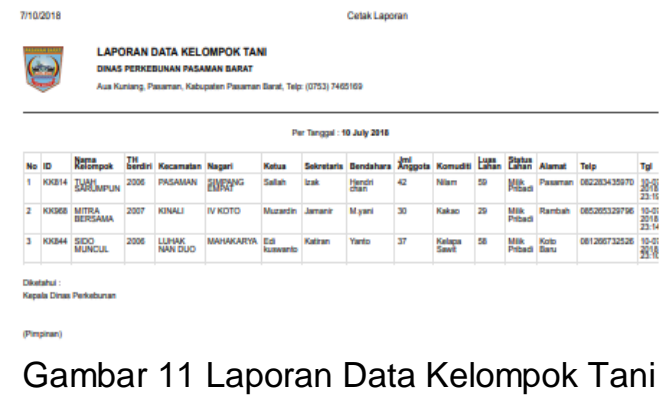

\section{Kesimpulan}

Berdasarkan hasil pembahasan proses penyaluran bibit di Dinas Perkebunan Kabupaten Pasaman Barat, maka dapat disimpulkan bahwa dengan adanya aplikasi ini, maka petani tidak kesulitan lagi mengetahui informasi tentang keberadaan bibit, dan petani bisa lebih cepat mengajukan permohonan untuk mendapatkan bibit tanpa harus mendatangi Dinas Perkebunan Kabupaten Pasaman Barat. Pengolahan data penyaluran bibit perkebunan oleh Dinas Perkebunan Kabupaten Pasaman Barat tidak lagi mengalami kesalahan. Pihak Dinas Perkebunan dan kelompok tani dapat mengakses informasi dengan cepat, tepat, akurat, dan relevan.

\section{Referensi}

Abdurahman, H., \& Riswaya, A. R. (2014). Aplikasi Pinjaman Pembayaran Secara Kredit Pada Bank Yudaha bakti. Jurnal Computech \& Bisnis, 8(2), 61-69. Retrieved from http://jurnal.stmikmi.ac.id/index.php/jcb/article/view/114/ 138

Alexander Setiawan. (2010). Pengaruh Kematangan, Kinerja Dan Perkembangan Teknologi Informasi di Perguruan Tinggi Swasta Yogyakarta Dengan Model Cobit Framwork. Seminar Nasional Informatika UPN "Veteran" Yogyakarta, semnasIF, 1826.

Arman, Wahyudi, D. E. (2019). Penerapan Sistem Pendukung Keputusan Penentuan Arah Minat Siswa Pada SMA N 14 Padang Berbasis Web Dengan Metode AHP. Jurnal.Umsb.Ac. Id/Index.Php/Rang Teknik Journal, 2(2), 179-186.

Arman, A., Elizamiharti, \& Muhammad Saf'an. (2019). Analisa dan Perancangan Sistem Informasi Penjualan Tanaman Hias Berbasis 
Online Sebagai Media Promosi Bagi Salman KS Flowers. Digital Zone: Jurnal Teknologi Informasi Dan Komunikasi, 10 (1), 64-76.

Atmojo, W. T., \& Sistem. (2019). Evaluasi Penggunaan Website Pada Pt. Ratu Nusantara Menggunakan Metode Usability Testing. PROSIDING ISSN: 2598 - 0246 E-ISSN: 2598-0238, IV, 37-47.

Budiman, A. (2017). Peran Teknologi Informasi Dan Komunikasi Dalam Pendidikan. Universitas Raden, Negeri Lampung, Intan, 8 (I), 31-43.

Click, J. J., Sistem, J., Dan, I., Informatika, M., Loveri, T., Komputer, S.,L. Perancangan Sistem Informasi Delivery Order Pupuk Merk Trubus Berbasi Web Pada CV. Prabu Siliwangi Padang. JURNAL J - CLICK, 5 (1), 98-106.

Dian, S., \& Pratiwi, P. (2017). Sistem Informasi Komunitas Jepret Mentaya Photography Sampit Berbasis Web. Jurnal Penelitian Dosen FIKOM (UNDA), 7(2).

Erna Kumalasari Nurnawati, E. S. (2018). Sosialisasi Manfaat Dan Bahaya Pemakaian Teknologi Informasi di Kalangan Anak-anak. Jurnal Dharma Bakti-LPPM IST AKPRIND Yogyakarta, 1(2), 123-132.

Loveri, T. (2007). Sistem Informasi Penyaluran Benih Dinas pertanian Tanaman Pangan Holtikutura Kabupaten Pasaman barat. Jurnal IImu Komputer, 6(1), 33-39.
Oksatriandhi, B., \& Santoso, E. B. (2014). Identifikasi Komoditas Unggulan Di Kawasan Agropolitan Kabupaten Pasaman. Jurnal Teknik ITS, 3 (1), C8-C11.

SAPUTRA, I., ANGGRENI, I., \& DHARMA, I. (2017). Pola Kemitraan Usaha Tani Kelapa Sawit Kelompok Tani Telaga Biru dengan PT. Sawindo Kencana melalui Koperasi di Kabupaten Bangka Barat Provinsi Bangka Belitung. Journal of Agribusiness and Agritourism, 6 (2), 249-258.

Sidik, M., Dan, J., Pi, R., Julianto, A., \& Tedyyana, A. (2019). Rancang Bangun Aplikasi Presensi Guru Sekolah, $x(x)$, 54-63.

Wardiana, W. (2002). Perkembangan Teknologi Informasi di Indonesia. Fakultas Teknik Universitas Komputer Indonesia (UNIKOM).

Yasdomi, K. (2015). Sistem Pendukung Keputusan Pemberian Kredit Modal Usaha Menggunakan Metode Weighted Product ( Studi Kasus Pada Bank Danamon Simpan Pinjam Ujung Batu ) Journal Of Computer Science Vol.1/No.1 : 92- 105 | 92, 1, 92-105.

Yendra Aprilla. (2018). Kabid Pariwisata Dinas Pariwisata Pemuda dan Olahraga Tanah datar Yendra Aprilla. wawancara dengan (Vol. 15). 